\title{
Report
}

\section{Developing a holistic accreditation system for medical universities of the Islamic Republic of Iran}

A. Yousefy, ${ }^{1}$ T. Changiz, ${ }^{1}$ N. Yamani, ${ }^{1}$ R.H. Zahrai ${ }^{2}$ and S. Ehsanpour ${ }^{2}$

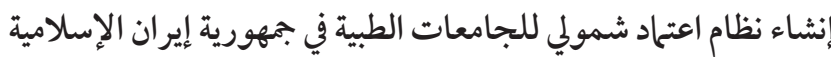

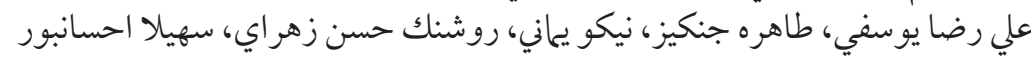

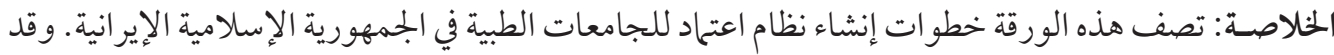

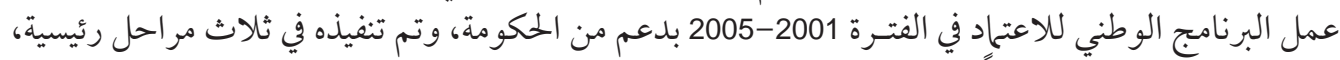

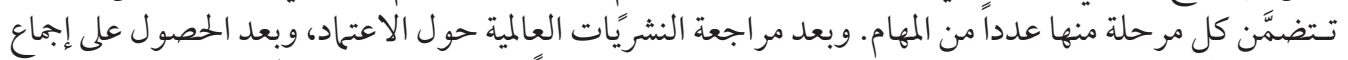

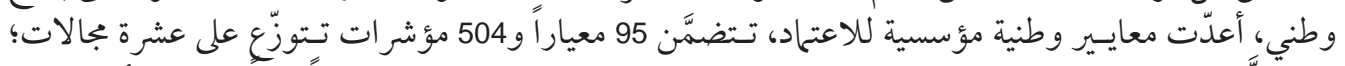

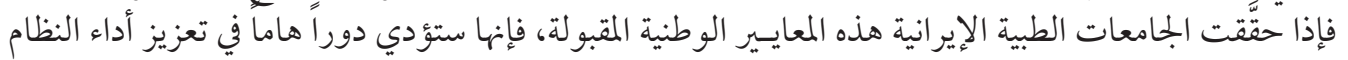

ABSTRACT This report describes the steps in the development of an accreditation system for medical universities in the Islamic Republic of Iran. The national accreditation project, supported by the government, was performed from 2001 to 2005 . The project was carried out in 3 main phases, each phase including a number of tasks. After a review of the international literature on accreditation and through national consensus, a set of national institutional accreditation standards was developed, including 95 standards and 504 indicators in 10 areas. By complying with accepted national standards, Iranian medical universities will play an important role in promoting health system performance.

\begin{abstract}
Élaboration d'un système d'accréditation global des facultés de médecine de la République islamique d'Iran

RÉSUMÉ Ce rapport décrit le processus l'élaboration d'un système d'accréditation des facultés de médecine en République islamique d'Iran. Le projet national d'accréditation a été réalisé de 2001 à 2005 avec l'aide du gouvernement. II s'est déroulé en trois phases principales, chacune impliquant un certain nombre d'opérations. Après examen de la littérature internationale sur l'accréditation et grâce à un consensus national, un ensemble de normes nationales d'accréditation institutionnelle comprenant 95 normes et 504 indicateurs dans 10 domaines a été mis au point. En respectant les normes reconnues au niveau national, les facultés de médecine iraniennes joueront un rôle important dans le bon fonctionnement du système de santé.
\end{abstract}

${ }^{1}$ Medical Education Research Centre; ${ }^{2}$ Nursing and Midwifery School, Isfahan University of Medical Sciences, Isfahan, Islamic Republic of Iran (Correspondence to N. Yamani: yamani@edc.mui.ac.ir). Received: 29/07/06; accepted: 20/12/06 


\section{Introduction}

In recent years there has been a rapid growth in the number of higher education institutions worldwide and in the variety of disciplines. Meanwhile, quality assurance and improvement, and maintaining this quality across different dimensions, have been a growing concern for both educators and governments. Moreover, shifts in attitudes and expectations in society have forced higher education to move toward establishing evaluation systems that are able to report the quality of the infrastructure, processes and outcomes.

The most critical issue for these systems is to identify the characteristics and indicators of quality in higher education. Quality in higher education was traditionally determined more by implicit perceptions of institutional reputation and characteristics than by explicit evidence of outcome and achievements [1]. Nowadays quality is defined in many ways, such as "fitness for purpose", "meeting the expectations of the consumer" or "satisfaction of clients" [2]. Quality should be measured across all parts of the institution or educational programme: input, process and output.

Accountability is another issue which requires that universities are responsible for their action and products (outcome), and hence, they have to accept external evaluation. There has been some resistance toward external evaluation of universities, who wish to protect their academic freedom and institutional autonomy. But the public's expectation of guarantees about the quality of the graduates on the one hand and the needs of universities for financial support on the other hand, compels universities to explore practical and effective ways to assure the community of their quality.

Measuring the quality of an educational institution is a difficult task, in terms of determining both what to measure and how best to measure it. Different evaluation models have been considered. Accreditation as a means for quality assurance has been highly approved and used by many educational institutions in different countries. In medical education, it is used as an evaluation model which provides support for continuous quality improvement in medical education and safeguards the medical profession [2]. Also, accreditation preserves long-held educational values of quality improvement and self-regulation while simultaneously addressing society's needs for accountability and quality assurance [3]. Accreditation is defined as "a process of external quality review used by higher education to scrutinize colleges, universities and educational programmes for quality assurance and quality improvement" [1].

Accreditation may be applied to institutions or programmes. Programme accreditation focuses on the individual programme's requirements to ensure the quality of inputs, process and output of the programme (for example, an internal medicine residency programme). In contrast, institutional accreditation considers the whole institution as an integral system and deals with the standards of system integrity and quality $[4,5]$.

The task of specifying standards or guidelines is central to the accreditation process. Standards constitute a new framework against which universities can measure themselves, and the accreditation of the educational institution can be initiated [6]. The accreditation framework and process must be in accordance with the political and operational structure of the government, in order to make it practicable. One of the most important elements of the reform process is adoption of national standards, which is a stage towards establishing a national accreditation system. 


\section{Medical schools in the Islamic Republic of Iran}

Although there are several well-established accreditation systems for individual programmes (mainly postgraduate residency programmes) in the Islamic Republic of Iran, the unique characteristics of medical schools in our country forced policy-makers to seek national standards for institutional accreditation of the schools. These characteristics include:

- A rapid increase in the number of medical schools. In recent decades these rose from 13 in 1979 to 48 in $2006[7,8]$.

- The dominance of the public sector in the medical education system. There are 38 medical schools affiliated to governmentcontrolled universities, while the others are private.

- A centralized educational curriculum. All medical schools follow a curriculum developed by the Iranian Ministry of Health and Medical Education (MOHME) [8].

- Unique responsibilities for community health. Since 1985 the Iranian universities of medical sciences were merged with MOHME. This integration made the universities of medical sciences responsible for all educational, research and health service activities in each province of the Islamic Republic of Iran [9].

Due to these factors, as well as the rapid growth in the number of medical universities and educational programmes in recent decades, establishing an accreditation system was an essential but challenging task. Quality assurance of higher education institutions in the Islamic Republic of Iran could no longer rely on governmental supervision and control. Hence, the undersecretary for education at MOHME called for an institutional accreditation project to design an accreditation system in accordance with the local situation of the Islamic Republic of Iran.

\section{Phases of the project}

The accreditation project in the Islamic Republic of Iran was a national project, supported by the undersecretary for education of MOHME and performed from 2001 to 2005. A national taskforce established at the Educational Development Centre of Isfahan University of Medical Sciences initiated the project, and took charge of performing the project's tasks and leading the main activities.

The project design was based on 5 main guidelines for the development of an accreditation system: setting the standards; establishing the accreditation body; setting a plan of action; starting self-assessment accreditation; and implementing and maintaining accreditation [10].

We outline here the 3 main phases of the project, each phase performed through a number of tasks.

\section{Phase 1: principles of standard setting}

Phase 1 was performed through 3 main tasks: developing an operational definition of institutional accreditation; establishing guiding principles for standard setting; and defining and determining the areas to be included in the accreditation.

In order to perform the first task, several study groups participated in reviewing the history of accreditation, accreditation procedures and accreditation standards in different countries [10-17]. Then, after differentiating between the domains of programme accreditation and institutional accreditation, the project focused on institutional accreditation. Finally, using these

المجلة الصحية لشرق المتوسط، منظمة الصحة العالمية، المجلد الخنامس عشر، العدد ب، 9 +. 
sources and an extensive literature review and also through consultation with international experts in accreditation, the following subjects were chosen to be considered in developing institutional accreditation: medical universities' performance in accordance with their mission and goals; inputs of medical universities; the process in medical universities; the potentials of medical universities; national and scientific values; the efficiency of medical universities; and the integration of activities in medical universities.

In performing the second task, the researchers developed the principles of standard setting. The goal of this task was to consider national requirements and social values in this process.

The third task was defining the different areas of accreditation. During focus group discussions and consultation with experts, it was decided to nominate 10 accreditation areas similar to the ones in other countries and accreditation organizations: (1) Mission and goals; (2) Management; (3) Resources and facilities; (4) Staff education; (5) Continuing education of graduates; (6) Faculty members; (7) Students' services; (8) Research; (9) Student education; (10) Clinical education. Each area of accreditation included a number of standards and, to make the standards understandable, applicable and measurable, a number of indicators were presented under each standard. The suggested standards and indicators were designed to ensure that the accredited university has appropriate purposes; has the resources necessary to accomplish its purposes; and will continue to accomplish them. Each standard requires that the institution assess its degree of effectiveness in each area covered by the standard and use the result of that assessment to improve and enhance the institution's ability to meet its mission [5].

\section{Phase 2: setting the standards}

Phase 2 included 2 main tasks: setting the standards and indicators; and defining assessment methods for the standards.

For the first task, the standards, and the indicators within each standard, were compiled using the viewpoint of experts, educators and stakeholders in each area. This was facilitated by researching standards compiled by institutional accreditation bodies in other countries [10-17], and international standards, such as those of the World Federation for Medical Education $[6,18]$. In the end, 95 standards and 504 indicators in the 10 areas (defined above) were compiled.

The second task was defining the assessment method for each indicator. The aim was to provide the universities with clear tasks for self-assessment and documentation, and to prepare a specific and objective tool for external evaluators.

No field testing has been done so far to explore the relevance and applicability of the proposed standards and indicators but the national consensus process (outlined next) helped to make the standards and indicators clear and applicable.

\section{Phase 3: national consensus}

Phase 3 of the project was to build a national consensus. The standards and related indicators were sent to 1171 experts in 40 medical universities throughout the country; experts in each area of accreditation commented on the standards and indicators in that area. The educational development centre in each university was responsible for distributing and collecting the questionnaires in that university. In total, 445 people returned the completed questionnaires. Based on the results of the consultation, some standards and indicators were revised, some were deleted and some were reclassified: the 
indicators which received more than $75 \%$ agreement on being a "must" standard were put under this category and the rest under the "should" category. The use of the word "must" indicates that the compliance with the standard is absolutely necessary to achieve the accreditation status. The word "should" indicates that meeting the standard is expected unless there are circumstances that obstruct full compliance.

Some of the indicators that were deleted after the national consensus were:

- "The amount of technical and scientific services by faculty members is determined." (This indicator was under the area: Faculty members).

- "The student representatives take part in planning for examinations." (Student education).

- "The role of advisors, faculty educational councils and the university educational council in educational decision-making is clear." (Student education).

Some of the standards that were added after the national consensus were:

- "There is easy access to teaching media and equipment in classrooms." (Resources and facilities).

- "Students are properly informed of bylaws regarding student violations." (Student services).

- "Ethical rules are considered in performing autopsies." (Clinical education).

The product of this final revision was 505 indicators under 95 standards in 10 areas of accreditation (some indicators were deleted and some were added so that the number of indicators and standards did not change during this process). A sample of the standards and indicators is shown in Table 1.

Two factors were important for obtaining institutional support for the initiative from the different faculties, who are the real stakeholders in the project. One of these was national consensus-building which acted by informing faculties of the accreditation philosophy and process as well as obtaining their support and cooperation. Also, the focus of some national meetings, such as medical education congresses, was on accreditation, which reinforced the initiative. The other factor is that the educational system in the Islamic Republic of Iran is mostly centralized, and all medical universities, despite having some autonomy, are obligated to follow MOHME regulations. As the accreditation questionnaires were distributed by MOHME, the universities felt obligated to comply. So, both obligation and encouragement were applied for obtaining support.

\section{National Commission for Accreditation}

After approving the accreditation standards, the Higher Council for Medical Sciences Planning, which acts under MOHME, developed the necessary by-laws for establishing a National Commission for Accreditation, and defining its position, membership and responsibilities.

The secretariat for the Commission was agreed to be within MOHME, and the members were assigned as follows: 10 members from under-secretaries and managers of MOHME as well as the secretaries of specialty and basic sciences councils; 3 members from university chancellors; and 5 university faculty members who are expert in the field of accreditation. The under-secretary for education heads the Commission. The faculty members and university chancellors are selected for a period of 2 years.

Some of the important responsibilities of the Commission are: developing new accreditation standards; continuous review- 


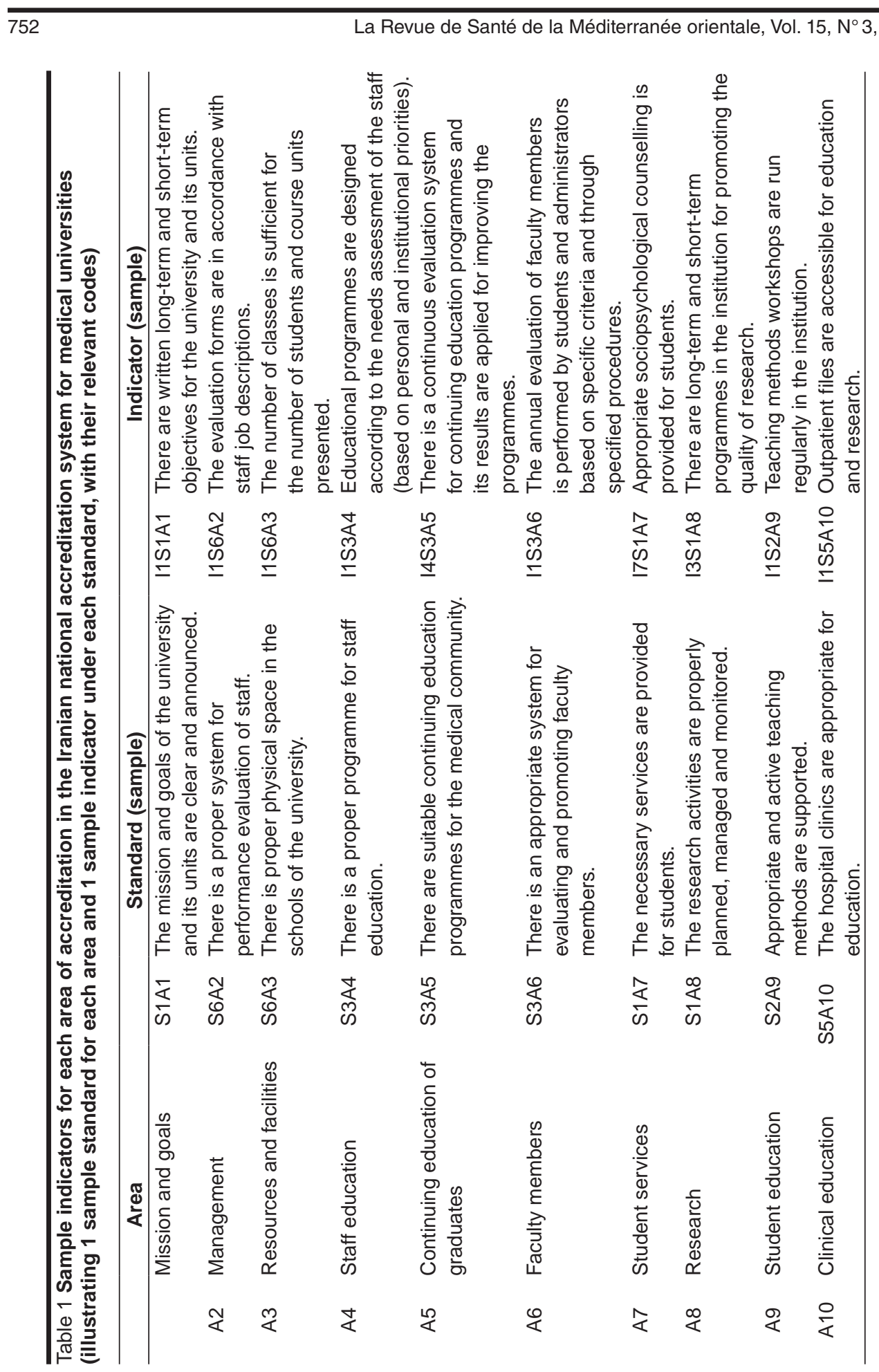

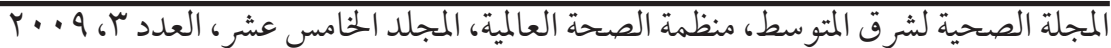


ing of accreditation standards and making necessary revisions; developing necessary by-laws for institutional accreditation; selecting competent faculty members for visiting teams; providing necessary education for the visiting teams; and helping medical universities in performing self-assessment.

The Commission will undertake its tasks by forming affiliated committees and also by delegating some tasks to the major universities. The main responsibilities of the Commission will be supervising the committees and approving by-laws and necessary rules. The decisions of the Commission will be communicated as for other decisions made at the ministry level.

The implementation process has already been started by establishing the Commission. The mode of implementation depends on the decisions of the Commission, but it has already planned educational workshops about the accreditation process for reviewers and professionals at the institutional level, which in turn can lead towards the institutionalization of accreditation in higher education.

\section{Discussion}

By developing national accreditation standards and indicators, this project aimed to propose a sound system for institutional accreditation designed to strengthen and sustain the quality and integrity of Iranian higher education institutions while making them worthy of public confidence.

The extent to which each educational institution accepts and fulfils the responsibilities inherent in the process of accreditation is a measure of its concern for quality in higher education and its commitment to achieving excellence in its endeavours [14]. Investigating the established accreditation process in other higher education institutions shows that the accreditation commission in those institutions has defined accreditation standards to assist both the institution and accreditation organization in defining institutional quality and educational effectiveness and in promoting the development and sharing of practices leading to the improvement of quality $[5,12]$.

Moreover, studying the areas and criteria of accreditation set by other institutions shows that most of them use similar areas approved by this project. For example, the Australian Medical Council proposed 10 main standards for accrediting basic medical education, 6 of which are the same as the accreditation areas in the present project and 4 of which are mainly concerned with programme accreditation [15]. The Southern Association of Colleges and Schools in the United States of America (USA) has considered accreditation standards in 8 main areas including: Mission; Governance and administration; Institutional effectiveness; Educational programmes; Faculty; Learning resources; Student affairs and services; and Resources [11]. These areas are almost the same as in the present project.

Another aspect of this project was developing indicators under each standard and specifying the method for measuring or determining the degree of fulfilment of each indicator, which can be used by the institution itself or the accreditation body. Some other accreditation organizations, such as the Western Association of Schools and Colleges in the USA, have identified guidelines for accreditation criteria that identify expected forms or methods of demonstrating performance [12]. However, many accreditation organizations have no specific indicators for demonstrating each standard or any guidelines to explain the method of assessing each criterion or standard. So, a unique feature of the standards developed by this project was identifying the indicators under each standard in each area and specifying the method of assessing

المجلة الصحية لشرق المتو سط، منظمة الصحة العالمية، المجلد الخامس عشر، العدد ب، 9 +. 
each indicator. By doing this, the institutions under review will not need to apply for interpretation of each standard. They will be able to go through a self-assessment review on their own and with minimal assistance from the accrediting body.

Another feature of the standards in this project was that they were designed to be relevant to the context of the Islamic Republic of Iran, such as the standards meeting the regulations made by MOHME concerning continuing education of graduates and its management, educational facilities (especially appropriate and adequate physical space), and specific policies in the management area.

Any accreditation system has to be adjusted to the economic and political structures of the society in which it will be used as well as the universities' management policies. Hence it should be noted that there were some limitations on the researchers' proposals for the National Commission for Accreditation. First, as the educational system in the Islamic Republic of Iran is centralized and all universities are either government-run or act under its regulations, specific members had to be considered for this Commission such as the minister, the under-secretary for education and so on. Secondly, as nongovernmental organizations in the Islamic Republic of Iran are not empowered to take part in these activities and programmes, representation on the Commission from students and the general public has not yet been considered. Of course, the composition of the Commission as well as the accreditation standards can be changed over time and based on new policies and decisions.

Overall institutional improvement is stimulated by the requirement that the accredited institution conducts periodic selfevaluation to identify what it does well, determine the areas in which improvement is needed, and develop plans to address needed improvements. While accreditation indicates an acceptable level of overall quality, any institution, however excellent, is capable of improvement, which must come from its understanding of its own strengths and weaknesses. Institutional improvement is also encouraged through the advice and counsel provided by the visiting team, which comprises experienced educators drawn primarily from accredited institutions, and by the publications of the accrediting body [5]. The purpose of considering "should" indicators in the present accreditation model was to encourage universities to make efforts toward improving their quality.

During the national consensus for approving the standards and indicators, the viewpoints of university administrators and experts were sought. The aim was to take advantage of their knowledge and experience to ensure that every area was well covered and every standard and indicator made good sense in the real situation of every institution by separating "must" and "should" standards.

On the other hand, the medical universities in the Islamic Republic of Iran vary in their size, facilities, number of students, resources, number of faculty members and so on. So evaluating them all by the same standards would be unfair. Providing the option of "must" and "should" standards was an attempt to overcome this problem. The university administrators know their own situation and can select each indicator as a "must" or "should" standard. Therefore, it is up to the universities to achieve "should" standards or move toward achieving them.

By performing self-assessment and accreditation periodically, each institution will try to fulfil the required standards and even move beyond the "must" standards. 
Therefore, the accreditation standards will need periodic refinement in response to changes following each accreditation as well as other changes that can happen in any institution over time. Other accreditation organizations either develop standards in a way to include a wide range of collegiate institutions, as evidenced by their differences in purpose, size, organization, scope, support and control [5], or assign a specific committee to periodically revise standards [16]. So, one of the next steps in establishing the accreditation system should be assigning a standard committee of experts to periodically revise the old standards and add new ones if needed. This has been considered in the approved by-laws concerning establishing the accreditation system for Iranian medical universities.

\section{Conclusion}

This project has taken an important step towards establishing an accreditation system for medical universities in the Islamic Republic of Iran. This will lead to improvement and quality assurance of higher education institutions. By complying with accepted national standards, the medical universities will play an important role in promoting health system performance.

Considering the international focus on the quality of higher education, and the World Health Organization's regional initiative to reform the education of health professional through accreditation [2], establishing a national accreditation system based on the results of this project could increase the international and regional credibility of Iranian medical universities.

\section{References}

1. The fundamentals of accreditation: what do you need to know? Washington DC, Council for Higher Education Accreditation, 2002.

2. Technical discussions, accreditation of hospitals and medical education institutions-challenges and future directions. Cairo, World Health Organization Regional Office for the Eastern Mediterranean, 2003.

3. Baker RL. Evaluating quality and effectiveness: regional accreditation principles and practices. Journal of academic librarianship, 2002, 28(1):3-7.

4. Accreditation in the United States (http:// www.ed.gov/admins/finaid/accred/accreditation.html, accessed 18 Januaryt 2009).

5. Evaluation manual. Bedford, Massachusetts, Association of Schools and Colleges, 1996.

6. International standards in medical education: assessment and accreditation of med- ical schools' educational programmes. A WFME position paper. The Executive Council, the World Federation for Medical Education. Medical education, 1998, 32:549-58.

7. Mohammadi A, Mojtahedzadeh R, Motarjemi R. [Iranian medical schools: database and ranking]. Tehran, Ministry of Health and Medical Education, 2003 [in Farsi].

8. Tavakol M, Murphy R, Torabi S. Medical education in Iran: an exploration of some curriculum issues. Medical education online, 2006, 11(5):1-8.

9. [Evaluation of the integration of medical education and health care system in the Islamic Republic of Iran]. Tehran, Deputy for Education, Ministry of Health and Medical Education, 2003 [in Farsi].

10. Accreditation handbook. Oregon, Northwest Association of Schools and Colleges, 1999.

المجلة الصحية لشرق المتو سط، منظمة الصحة العالمية، المجلد الخامس عشر، العدد ب، 9 +. 
11. Criteria for accreditation. Decatur, Georgia, Southern Association of Colleges and Schools, United States, 2004.

12. Handbook of accreditation. Burlingame, California, Western Association of Schools and Colleges, 2001.

13. Accreditation of higher education institutions: an overview. Tempe, Arizona, Arizona North Central Association of Colleges and Schools, United States, 2001.

14. Characteristics of excellence in higher education. Philadelphia, Pennsylvania, Middle State Commission on Higher Education, 2002.

15. Assessment and accreditation of medical schools: standards and procedures.
Kingston, New South Wales, Australian Medical Council, 2002.

16. Functions and structure of a medical school: standards for accreditation of medical education programs leading to the $M D$ degree. Washington DC, Liaison Committee on Medical Education, 2002.

17. Accreditation criteria. Taipei, Taiwan Medical Accreditation Council (http:// www.nhri.org.tw/nhri_org/mc/main4.html, accessed 18 January 2009).

18. Basic medical education. WFME global standards for quality improvement. Copenhagen, World Federation for Medical Education, 2003.

\section{Management effectiveness initiatives}

The management of health care is a pivotal factor in the delivery of effective health service with growing recognition of the key role that non-clinical activities play in the way that health care is delivered. Management effectiveness is crucial in all health care settings: hospitals, primary health care clinics, mobile units, laboratories and pharmacies. The WHO Regional Office for the Eastern Mediterranean (EMRO) works in partnership with ministries of health of the Region to strengthen the way in which health care facilities and professionals are managed. The ultimate aim is to improve their functioning by working towards greater effectiveness, efficiency, quality and coverage of services which lead to better health outcomes.

EMRO offers technical assistance in developing key health management tools and approaches such as hospital accreditation, licensing of health professionals and facilities, patient safety, quality assurance, the introduction of family practice, evidence-based medicine, decentralization, hospital autonomy, community health management and the district health system approach.

Further information on hospital accreditation in the Region and EMRO's work in this area can be found at: http://www.emro.who.int/ mei/HA.htm. 